\title{
Drought increases chlorophyll content in stems of Vitis interspecific hybrids
}

\author{
Laura Rustioni (D) Davide Bianchi
}

Received: 8 October 2020/Accepted: 22 January 2021 / Published online: 10 February 2021

(C) The Author(s) 2021

\begin{abstract}
Plants respond to drought stress through different physiological mechanisms. To highlight a specific adaptation strategy related to stem photosynthetic activity, woody tissue pigmentation was studied. In this work, 25 Vitis hybrids were studied in two experimental vineyards: one of them with sufficient water availability and the other showing drought stress. 1500 reflectance spectra of woody tissues were collected. Beside the spectral elaboration and interpretation, indexes for the pigment quantification were calculated. The content and the proportion in chlorophylls ( $a$ and $b$ ) in stems were significantly modified in response to water stress. Genotypes were classified based on their plasticity/elasticity and adaptive/susceptible behavior. The cluster analysis produced 4 main groups based on their average spectra and on the spectral variations between watered and stress
\end{abstract}

Supplementary Information The online version contains supplementary material available at https://doi.org/10.1007/ s40626-021-00195-0.

L. Rustioni ( $₫)$

DISTEBA-Dipartimento di Scienze e Tecnologie Biologiche ed Ambientali, Centro Ecotekne-Università del Salento, via Provinciale Monteroni, 73100 Lecce, Italia

e-mail: laura.rustioni@unisalento.it

D. Bianchi

DISAA-Dipartimento di Scienze Agrarie e Ambientali-Università Degli Studi Di Milano, via Celoria 2, 20133 Milano, Italia conditions. The most interesting genotypes concerning this trait were pointed out. Nevertheless, this adaptation mechanism could also be due to an increased detoxification necessity related to other physiological disfunctions caused by water stress. A multi-parameter approach is encouraged for phenotyping of abiotic stress tolerant plant selection. In the next future, this work will support the release of new drought tolerant rootstocks for viticulture.

Keywords Stem photosynthesis - Abiotic stress . Tolerance mechanisms - Reflectance spectroscopy · Pigmentation · Grapevine

\section{Introduction}

The consequences of drought in plants are mainly due to the interlinked effects on hydraulic failure and carbon starvation (Vandegehuchte et al. 2015). In viticulture, a major strategy to face drought is the selection of tolerant interspecific hybrids to be used as rootstocks (Lovisolo et al. 2016; Zhang et al. 2016).

Drought affects leaf photosynthetic activity (Vaz et al. 2016) by modifying the plant photosynthetic activity and inducing stomata closure with the consequent decrease in the ratio of $\mathrm{CO}_{2}$ to $\mathrm{O}_{2}$. In extreme cases, intense water stress lead to leaf senescence and abscission, to reduce plant transpiration and water 
consumption (Munné-Bosch and Alegre 2004; Fini et al. 2013; Herrera et al. 2017).

Considering the devastating effects of drought to leaf activity, tolerance mechanisms could involve the adaptation of other photosynthetic organs. In particular, stems frequently contribute to a significant proportion of the plant carbon fixation, being the primary photosynthetic organs in mostly of the desert CAM species (Nilsen 1995; Aschan and Pfanz 2003; Cernusak and Cheesma 2015). A different strategy of woody tissues carbon fixation is made by corticular photosynthesis (involving cortex of new shoots and/or ray parenchyma cells and/or bark), that has been mainly documented in temperate-zone trees (Nilsen 1995; Aschan and Pfanz 2003; Cernusak and Cheesma 2015; Tikhonov et al. 2017). Bark layers, in particular cortex, are the main photosynthesis sites in stems. Nevertheless, green tissues can also be observed in deeper layers, such as ray cells of the wood, with the main role of diminish the danger of anaerobiosis (Aschan and Pfanz 2003). In fact, the primary role of corticular photosynthesis appears to be in the recycle of respired carbon dioxide, due to the very high $\mathrm{CO}_{2}$ concentration (ranging about 1-26\%) inside trunks and woody branches (Nilsen 1995; Cernusak and Cheesma 2015; Vandegehuchte et al. 2015; Tikhonov et al. 2017). Under water stress, when atmospheric $\mathrm{CO}_{2}$ uptake is limited, woody tissue photosynthesis, using endogenously respired $\mathrm{CO}_{2}$, is expected to gain more importance (Vandegehuchte et al. 2015). Stem photosynthesis allows the maintenance of physiological activity during stress; it increases the water use efficiency; it provides the carbon source for new organs; and it avoids hypoxia, raising the internal $\mathrm{O}_{2}$ concentration (Ávila et al. 2014; Vandegehuchte et al. 2015).

Corticular photosynthesis has been demonstrated to significantly contribute to the overall plant carbon economy (Saveyn et al. 2010; Vandegehuchte et al. 2015). Considering different species, recycling of $\mathrm{CO}_{2}$ by woody tissue photosynthesis can instantaneously offset about $72 \%$ of summer carbon loss in stems and branches (Vandegehuchte et al. 2015). In Populus tremula, bark contains up to $42 \%$ of the total tree chlorophyll (Aschan and Pfanz 2003). In this species, the contribution of the woody tissue photosynthesis to the overall carbon balance in the vegetative period has been estimated around $10-15 \%$, but this percentage is expected to increase under drought stress due to the limited leaf activity (Vandegehuchte et al. 2015). In Vitis spp., a higher contribution of stem photosynthesis should be expected: being lianas, these plants have an important annual growth with new, young and with thin bark, photosynthetically active shoots. It is worth to notice that light transmission through bark is drastically reduced with advancing age of the twig or branch segments (Aschan and Pfanz 2003). Beside the light intensity, other micro-environmental factors (e.g., $\mathrm{CO}_{2} / \mathrm{O}_{2}$ proportions, $\mathrm{pH}$ ) differ between chlorenchyma of leaves and stems. Tikhonov et al. (2017) studied the different grapevine green tissues, demonstrating distinctive features of the stem photosynthetic apparatus characteristics such as specific pigment proportions and higher tolerance to low temperatures.

The recycling photosynthesis, increasing the carbon use efficiency, rise the plant water-use efficiency too (Aschan and Pfanz 2003; Cernusak and Cheesma 2015). Moreover, it has been found that bark water-use efficiency is 50 times larger than in leaves in Western white pine (Cernusak and Marshall 2000; Cernusak and Cheesma 2015).

Stem recycling photosynthesis is also less susceptible than leaf photosynthesis to both high and low temperatures (Cernusak and Cheesma 2015; Tikhonov et al. 2017). Drought is often accompanied by hot weather, however, while the stomata closure imposes a decrease in the ratio of $\mathrm{CO}_{2}$ to $\mathrm{O}_{2}$ in leaves, the bark keeps this proportion relatively high due to the exponential increase of dark respiration (Cernusak and Cheesma 2015). Furthermore, corticular photosynthesis helps to keep the plant hydraulic integrity, maintaining the osmotic potential of living tissues; preserving the turgor and phloem functionalities; and supporting the process of xylem refilling after embolism (Cernusak and Cheesma 2015; Vandegehuchte et al. 2015).

Finally, because stem recycling photosynthesis relies on internally produced $\mathrm{CO}_{2}$, the development of a low-permeability tissues will increase the overall recycling rate, beside the reduction of water loss (Cernusak and Cheesma 2015). This mechanism is coherent with the high correlation among drought tolerance and wood hydrophobicity found in Vitis spp. by Rustioni et al. (2016).

The crucial role of stems in plant water management has been clearly discussed by Tyree and Ewers (1991), nevertheless, its importance is often underestimated. 
This work aims at investigating the effect of drought on the chlorophyll contents in woody tissues of Vitis hybrids to confirm the hypothesis of a possible adaptation mechanism to water stress based on corticular photosynthesis.

\section{Materials and methods}

The plant material used in this experiment, is the same already described in Bianchi et al. (2018) and Bianchi et al. (2020). 25 grapevine rootstocks (Vitis spp. hybrids) have been studied: G.03; G.05; G.12; G.13; G.16; G.19; G.21; G.23; G.24; G.25; G.26; G.27; G.28; G.29; G.30; G.34; G.69; G.71; G.73; G.75; G.76; G.77; G.81; G.82; G.83. Information concerning the genetic characteristics will be available in Migliaro et al. (2019). The study was undertaken in 2017 in two different experimental vineyards sited in Lombardy (Italy): Arcagna (45.340276N, $9.449786 \mathrm{E}, 83 \mathrm{~m}$ a.s.l.) and Riccagioia $(44.984783 \mathrm{~N}, 9.089038$ E, $133 \mathrm{~m}$ a.s.l.). During that vintage, the two areas were characterized by different weather conditions (further details concerning the meteorological conditions in the two experimental sites in 2017 are reported in SI 1). Plants grown in Arcagna had a sufficient water availability, while in Riccagioia vines underwent drought stress. Figure 1 summarizes the site characterization discussed in Bianchi et al. (2018), in terms of water status. The water availability of plants was

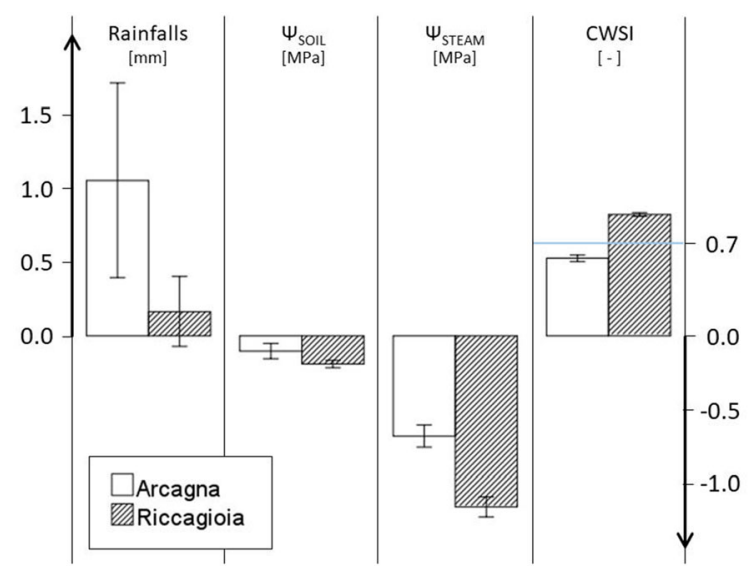

Fig. 1 Water availability and drought stress characterizations in the two experimental site. The blue line in the CWSI graph indicate the water stress threshold proposed by Matese et al. (2018) and Bellvert et al. (2014) higher in Arcagna than in Riccagioia during the months July and August, as shown by the average daily precipitations and the soil water potential $\left(\Psi_{\text {SOIL }}\right)$ reported in the figure. In that period, the total rainfall amounted at $65.2 \mathrm{~mm}$ and $10.2 \mathrm{~mm}$ in Arcagna and Riccagioia respectively. Indeed, plants in Riccagioia generally suffered the water stress, as proved by the low steam water potential $\left(\Psi_{\text {STEAM }}\right)$, recorded by a Scholander pressure chamber. Crop Water Stress Index (CWSI), measured by a thermal camera, confirmed higher water stress in Riccagioia than in Arcagna. Furthermore, CWSI in Riccagioia oversteps the water stress threshold of 0.7 reported in literature (Bellvert et al. 2014; Matese et al. 2018) for Vitis vinifera. Contrarily, plants in Arcagna grew under well-watered conditions and they generally were not affected by high water stress (Fig. 1).

Stems were collected in the middle of December 2017, concurrently with the winter pruning, during vine dormancy to have a higher sample stability. Three stems per genotype were collected for wood reflectance spectra measurements. In each site, 30 woody oblique sections per genotype (10 biological replications in each stem) were obtained using a penknife. Samples were taken from the middle-basal part of the shoots (between the 5th and the 10th node). Sections were obtained from the middle part of the internodes. Buds were not considered due to the different morphology of the shoot in proximity of the nodes. Examples of woody sections are shown in Fig. 2. Spectra were collected directly on the solid materials, without extractions, on the vascular tissues.

The Jaz System spectrometer (Ocean Optics) used in this experiment was set up as already described in Bianchi et al. (2018).

Each spectrum was normalized at $800 \mathrm{~nm}$ and, then, the multiplicative inverse was calculated to highlight the absorbance bands $\left(1 / \mathrm{N}_{800}\right)$. To show the variations in wood pigmentation due to drought, the difference among each spectrum collected in Riccagioia with the average spectrum of the same genotype grown in Arcagna was calculated $\left(\Delta 1 / \mathrm{N}_{800}\right)$.

Total chlorophyll content was estimated by using the formula proposed by Merzlylyak et al. (2003):

$$
C h I=R_{800} / R_{678}
$$

To calculate the proportion among pigments, the chlorophyll $a$ and chlorophyll $b$ were estimated by the formulas proposed by Rocchi et al. (2016): 


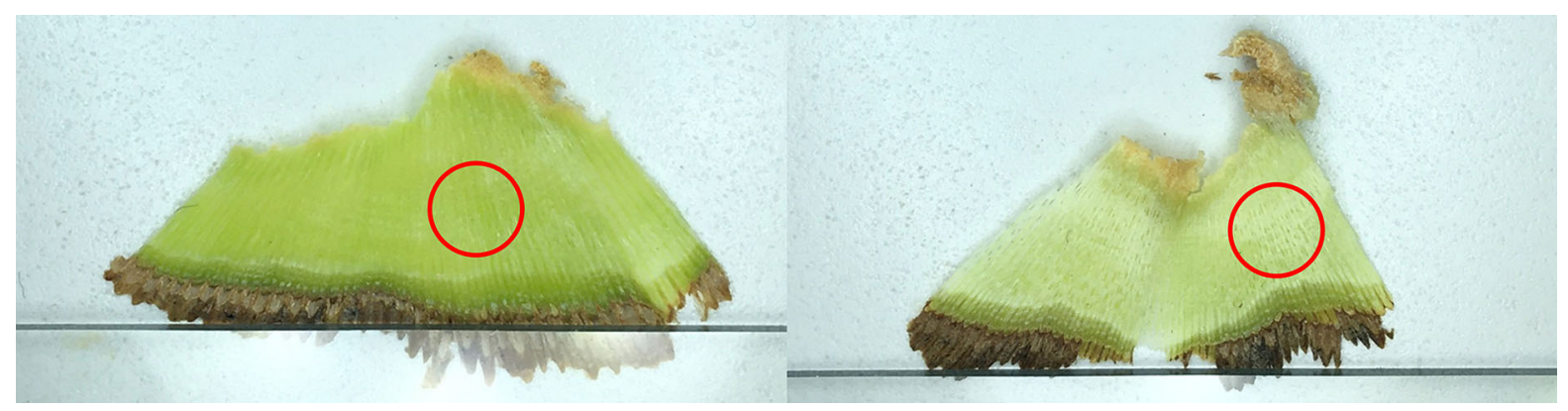

Fig. 2 Examples of woody sections analyzed in this work. Red circles indicate examples of the area measured through the reflectance spectroscopy probe. (Color figure online)

$C_{\mathrm{a}} I=\log \left[\left(\frac{R_{800}}{R_{675}}\right)-\left(\frac{R_{800}}{R_{660}}\right)\right]$

$C_{\mathrm{b}} I=\log \left[\left(\frac{R_{800}}{R_{650}}\right)-\left(\frac{R_{800}}{R_{630}}\right)\right]$

$R_{n}=$ reflectance value at $\mathrm{n}$ wavelength

Spectra are presented as averages \pm errors $(95 \%$ Confidence Intervals). Analysis of variance (ANOVA) was performed at $\alpha \leq 0.05$, in order to identify single effects of factors and their interactions. Duncan test was chosen for post-hoc comparisons. The average spectra and the difference between stressed and wellwatered samples of each genotype were submitted to hierarchical clustering. The grouping was performed using the UPGMA method (Unweighted Pair Group Method with Arithmetic Mean) using 2296 parameters for clustering (each spectrum or differential spectrum is composed by 1148 wavelength). Indexes were elaborated using Microsoft Office Excel and SPSS statistical software (IBM SPSS Statistics 24).

\section{Results}

Figure 3a reports the average spectrum $\left(1 / \mathrm{N}_{800}\right)$ of the woody tissues of each genotype. Vertical lines are at $490 \mathrm{~nm} ; 650 \mathrm{~nm}$ and $678 \mathrm{~nm}$. The peak at the highest wavelength $(678 \mathrm{~nm})$ is characteristic of a chlorophyll $a$ absorption band, while the shoulder around $650 \mathrm{~nm}$ indicates the chlorophyll $b$ contribution. The band around $490 \mathrm{~nm}$, mainly includes the absorption of chlorophylls in the blue region, carotenoids and oxidized phenolics.
In Fig. 3a, it is possible to observe a continuum of the chlorophyll concentration variability among genotypes. Nevertheless, the variability within the same rootstock is much lower than the one observed among different genotypes, as demonstrated by the nonoverlapping error bars shown in Fig. $3 b$ concerning the extreme cases of G.76 and G.81.

Water stress significantly modified the spectral signature in the woody tissues. Figure 4 reports the average $\Delta 1 / \mathrm{N}_{800}$ spectra (stressed-watered) and the relative error bars. The observed positive values indicate the increased absorption in drought grown plants, due to a higher concentration of pigments. Furthermore, the shape in the red region of the $\Delta 1$ / $\mathrm{N}_{800}$ spectra (stressed-watered), is different with respect to the woody tissue signature (Fig. 3). In particular, the shoulder at $650 \mathrm{~nm}$ has nearly the same intensity as the main band at $678 \mathrm{~nm}$. This indicates a variation in the proportion of the chlorophyll $a$ and $b$, as shown in Table 1 .

Rootstock genotypes represent the main source of the Chlorophyll Index (ChI) variability (57.7\%), whereas the water availability factor affects the $26.0 \%$ of the total variance. Contrarily, the variability of Chlorophyll $a$ and Chlorophyll $b$ proportion $\left(\mathrm{C}_{\mathrm{a}} \mathrm{I} /\right.$ $\left.\mathrm{C}_{\mathrm{b}} \mathrm{I}\right)$ is more explained by the water availability $(55.5 \%)$ than genotype factor $(37.0 \%)$. Analysis of variance highlighted significant differences between genotypes $(\alpha=0.000)$ and between water availability ( $\alpha=0.000$ ) in both chlorophyll content and proportion. Furthermore, genotypes and water availability reported significant interaction $(\alpha=0.000)$, which represented the $15.0 \%$ and the $7.0 \%$ of $\mathrm{ChI}$ and $\mathrm{C}_{\mathrm{a}} \mathrm{I} /$ $\mathrm{C}_{\mathrm{b}} \mathrm{I}$ variances, respectively. The error percentages of variance settled at the low levels of $1.5 \%$ for $\mathrm{ChI}$ and $0.0 \%$ for $\mathrm{C}_{\mathrm{a}} \mathrm{I} / \mathrm{C}_{\mathrm{b}} \mathrm{I}$ proportion. 

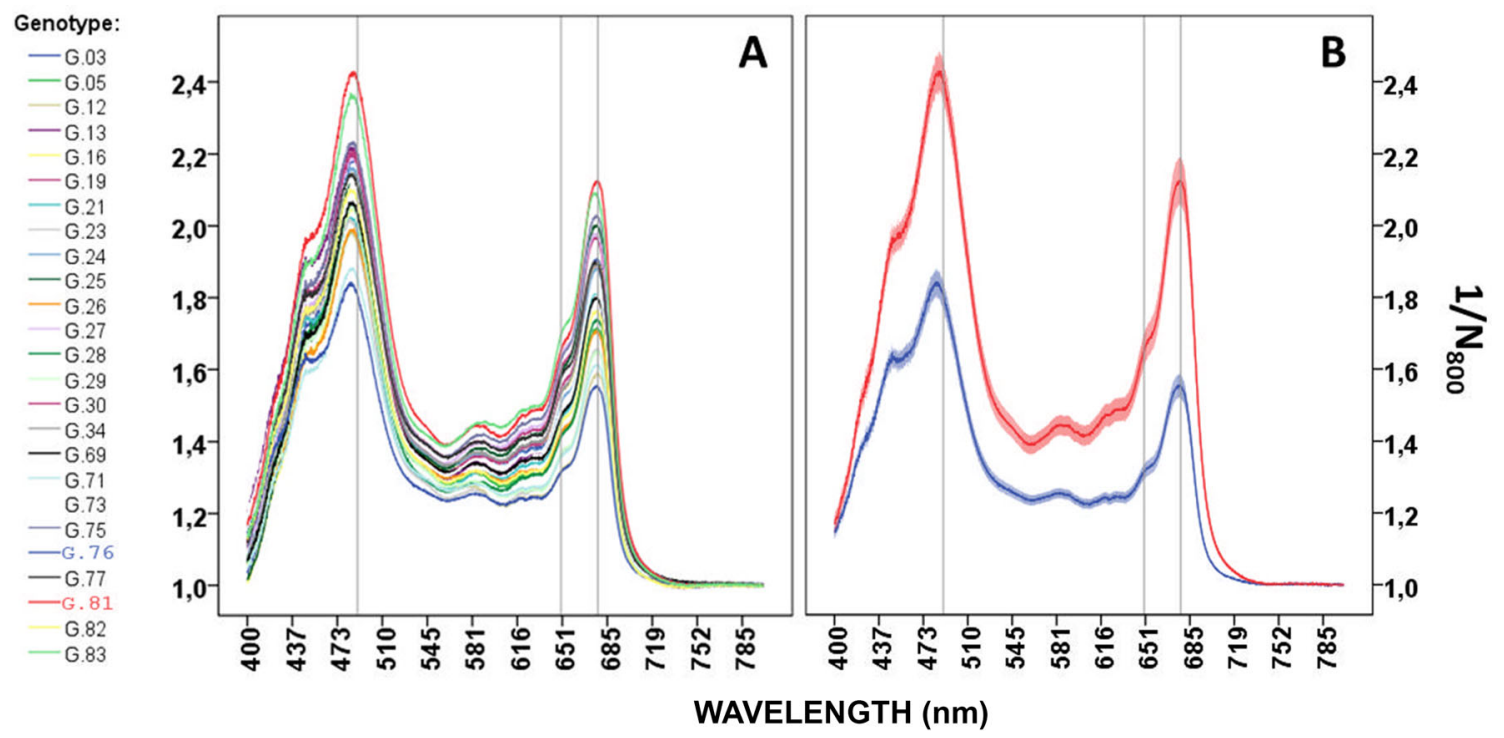

Fig. 3 Average $1 / \mathrm{N}_{800}$ reflectance spectra of each genotype (a) and of the extreme cases G.81 and G.76 with error bars (b). Vertical lines are at $490 \mathrm{~nm} ; 650 \mathrm{~nm}$ and $678 \mathrm{~nm}$

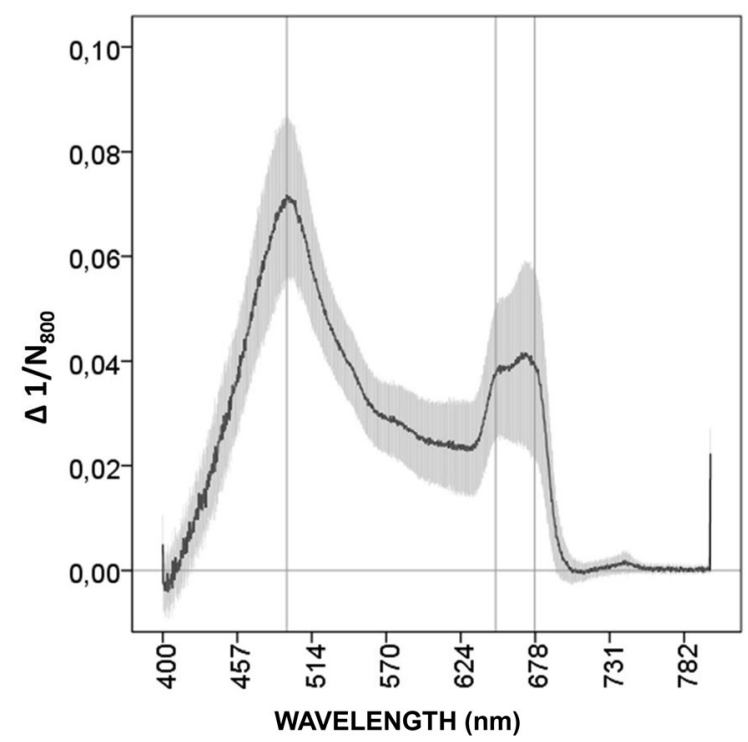

Fig. 4 Average $\Delta 1 / \mathrm{N}_{800}$ spectra (stressed-watered) of all the studied genotypes and relative error bars. Positive values indicate pigment accumulation in response to drought. Vertical lines are at $490 \mathrm{~nm} ; 650 \mathrm{~nm}$ and $678 \mathrm{~nm}$

Table 1 shows the average performance of rootstocks in terms of $\mathrm{ChI}$ and $\mathrm{C}_{\mathrm{a}} \mathrm{I} / \mathrm{C}_{\mathrm{b}} \mathrm{I}$, their standard deviation, significant differences between genotypes and significant differences of each genotype in different water conditions.
Genotypes could be classified based on their elastic or plastic behavior in response to water stress, according to Bianchi et al. (2018). Elastic genotypes keep similar performances independently of the environmental conditions. Plastic genotypes undergo significant modifications in their phenotypical expression as a consequence of the environment, with a susceptive or adaptive behavior depending on the negative or positive response. Taking into account the genotype response to drought, about half of rootstocks showed an elastic behavior concerning the total chlorophyll content (Table 1). This number was reduced considering the $\mathrm{C}_{\mathrm{a}} \mathrm{I} / \mathrm{C}_{\mathrm{b}} \mathrm{I}$ ratio. Mostly of the genotypes showed a plastic-adaptive behavior, especially concerning the $\mathrm{C}_{\mathrm{a}} \mathrm{I} / \mathrm{C}_{\mathrm{b}} \mathrm{I}$ ratio (Table 1 ). Only genotypes G.03 and G.30 stood out showing a plastic-susceptible response (Table 1). In fact, they showed significant differences among sites $(\mathrm{P} \geq 0.01)$ as expected in plastic genotypes, but they had lower values in drought conditions for both $\mathrm{ChI}$ and $\mathrm{C}_{\mathrm{a}} \mathrm{I} / \mathrm{C}_{\mathrm{b}} \mathrm{I}$, demonstrating a susceptible response. G.24 and G.16 appeared to be particularly interesting, due to their strong adaptivity (they had the highest $\mathrm{ChI}$ increase due to drought) as well as G.81 and G.83, having the highest chlorophyll concentration in both the studied environments. Details concerning the characteristics of each genotype in both the experimental sites are reported in SI 2. 
Table 1 Average performance of genotypes and their standard deviation are reported for $\mathrm{ChI}$ and $\mathrm{C}_{\mathrm{a}} \mathrm{I} / \mathrm{C}_{\mathrm{b}} \mathrm{I}$ ratio

\begin{tabular}{|c|c|c|c|c|}
\hline \multirow{2}{*}{$\frac{\text { Rootstock }}{\text { G.03 }}$} & \multicolumn{2}{|l|}{$\mathrm{ChI}$} & \multicolumn{2}{|l|}{$\mathrm{C}_{\mathrm{a}} \mathrm{I} / \mathrm{C}_{\mathrm{b}} \mathrm{I}$} \\
\hline & $1.90 \pm 0.27 * *$ & ghi & $0.58 \pm 0.07 * *$ & $\mathrm{a}$ \\
\hline G.05 & $1.71 \pm 0.19 * *$ & $\mathrm{~cd}$ & $0.66 \pm 0.06$ & defg \\
\hline G.12 & $1.59 \pm 0.18$ & $a b$ & $0.58 \pm 0.06$ & $\mathrm{a}$ \\
\hline G.13 & $1.89 \pm 0.21$ & $\mathrm{gh}$ & $0.67 \pm 0.05^{* *}$ & $\mathrm{~g}$ \\
\hline G.16 & $1.90 \pm 0.26^{* *}$ & $\mathrm{gh}$ & $0.60 \pm 0.05^{* *}$ & $\mathrm{~b}$ \\
\hline G.19 & $1.96 \pm 0.21 * *$ & hil & $0.71 \pm 0.06^{* *}$ & $\mathrm{~h}$ \\
\hline G.21 & $1.81 \pm 0.14$ & ef & $0.62 \pm 0.06$ & $\mathrm{bc}$ \\
\hline G.23 & $1.66 \pm 0.17 * *$ & $\mathrm{bc}$ & $0.62 \pm 0.05$ & $\mathrm{bc}$ \\
\hline G.24 & $1.88 \pm 0.30^{* *}$ & fg & $0.61 \pm 0.05^{* *}$ & $\mathrm{~b}$ \\
\hline G.25 & $2.00 \pm 0.13$ & 1 & $0.64 \pm 0.04$ & def \\
\hline G.26 & $1.70 \pm 0.24^{* *}$ & $\mathrm{~cd}$ & $0.66 \pm 0.06^{* *}$ & fg \\
\hline G.27 & $1.97 \pm 0.16$ & il & $0.83 \pm 0.07 * *$ & $\mathrm{~m}$ \\
\hline G.28 & $1.74 \pm 0.15$ & de & $0.62 \pm 0.05^{*}$ & $\mathrm{bc}$ \\
\hline G.29 & $1.65 \pm 0.14^{*}$ & $\mathrm{bc}$ & $0.65 \pm 0.08^{*}$ & def \\
\hline G.30 & $1.89 \pm 0.22 * *$ & $\mathrm{gh}$ & $0.71 \pm 0.10^{* *}$ & $\mathrm{~h}$ \\
\hline G.34 & $1.89 \pm 0.20$ & $\mathrm{gh}$ & $0.64 \pm 0.06^{*}$ & $\mathrm{~cd}$ \\
\hline G.69 & $1.79 \pm 0.14^{* *}$ & e & $0.64 \pm 0.06^{* *}$ & cde \\
\hline G.71 & $1.61 \pm 0.12 *$ & $\mathrm{ab}$ & $0.65 \pm 0.04 * *$ & defg \\
\hline G.73 & $1.81 \pm 0.21$ & ef & $0.77 \pm 0.05$ & 1 \\
\hline G.75 & $2.02 \pm 0.26$ & $\operatorname{lm}$ & $0.66 \pm 0.09 * *$ & efg \\
\hline G.76 & $1.55 \pm 0.12 * *$ & $\mathrm{a}$ & $0.62 \pm 0.04 * *$ & $\mathrm{bc}$ \\
\hline G.77 & $1.89 \pm 0.22$ & $\mathrm{gh}$ & $0.78 \pm 0.06^{* *}$ & 1 \\
\hline G.81 & $2.12 \pm 0.25^{* *}$ & $\mathrm{n}$ & $0.58 \pm 0.06^{* *}$ & $\mathrm{a}$ \\
\hline G.82 & $1.76 \pm 0.11$ & de & $0.69 \pm 0.03 * *$ & $\mathrm{~h}$ \\
\hline G.83 & $2.08 \pm 0.33$ & $\mathrm{mn}$ & $0.75 \pm 0.07 * *$ & $\mathrm{i}$ \\
\hline
\end{tabular}

Differences between genotypes are evidenced by Duncan test and shown by letters. Significance of the differences among sites are indicated by $\operatorname{stars}(* \mathrm{P} \geq 0.05 ; * * \mathrm{P} \geq 0.01)$. The genotypes with significant better performances in drought conditions are reported in bold, indicating an adaptive response to water stress

The cluster analyses grouped the genotypes based on their $1 / \mathrm{N}_{800}$ and $\Delta 1 / \mathrm{N}_{800}$ spectra (resulting in a total of 2296 variability factors). The dendrogram showed a first split-up dividing the most interesting genotypes (groups 3 and 4) from the others (groups 1 and 2). Group 4 included rootstocks having the strongest adaptivity to drought (G.16 and G.24), confirmed by the high values of the $\Delta 1 / \mathrm{N} 800$ spectrum (Fig. $5.4 \mathrm{~b}$ ). Group 3 included G.81 and G.83, characterized by the highest pigment concentrations in woods, as demonstrated by the $1 / \mathrm{N}_{800}$ spectrum reported in Fig. 5.3a, as well as a good adaptivity (Fig. 5.3b). Group 1 is definitely less interesting than groups 3 and 4 . In group 1 , the adaptation mechanism is still present (Fig. 5.1b), but it is less intense than the one observed in groups 3 and 4, coherently with the significant $\mathrm{ChI}$ increase between watered and stressed conditions in mostly of the genotypes (Table 1). However, the average pigment concentration within this group is generally low (Fig. 5.1a). Finally, group 2 includes genotypes in which drought reduced the woody tissue pigmentation (Fig. 5.2b). Observing the data reported in Table 1 , it is possible to notice that, in these genotypes, water stress generally did not produce significant modifications in ChI, with the exception of three genotypes (G.03, G.30 and G.19) in which this index decreased. Decreasing the similarity threshold in group 2, G.03 and G.30 are separated from the others (Fig. 6). These genotypes are the only ones showing a plastic-susceptible response to drought, in both the $\mathrm{ChI}$ and $\mathrm{C}_{\mathrm{a}} \mathrm{I} / \mathrm{C}_{\mathrm{b}} \mathrm{I}$ ratio (Table 1 ).

In Fig. 6 genotypes are compared under watered and stressed conditions in terms of $\mathrm{ChI}$ in woody tissues. The average performance of all genotypes (1.83) is used as benchmark to identify rootstock behaviors. Genotypes reporting similar values (with respect to the benchmark) under both conditions, are represented by stars when they have high performances, otherwise they are represented by squares. Drought susceptible genotypes report high performance only under watered conditions and they are represented by facing down triangles, while genotypes exceeding the benchmark only under stressed conditions are shown as facing up triangles. Groups obtained by the cluster analyses are reported in different colors and centroids are highlighted by lines connecting each cluster. The perfect separation among groups in Fig. 6, based on the ChI measured in the two conditions, confirmed, among the 2296 variability factors considered in the cluster analysis, the central role of chlorophyll content and variability, in the similarity evaluation. Once again, this analysis confirmed G.81; G.83; G.24 and G.16 as the most interesting genotypes and G.30 and G.03 as the worst ones. 

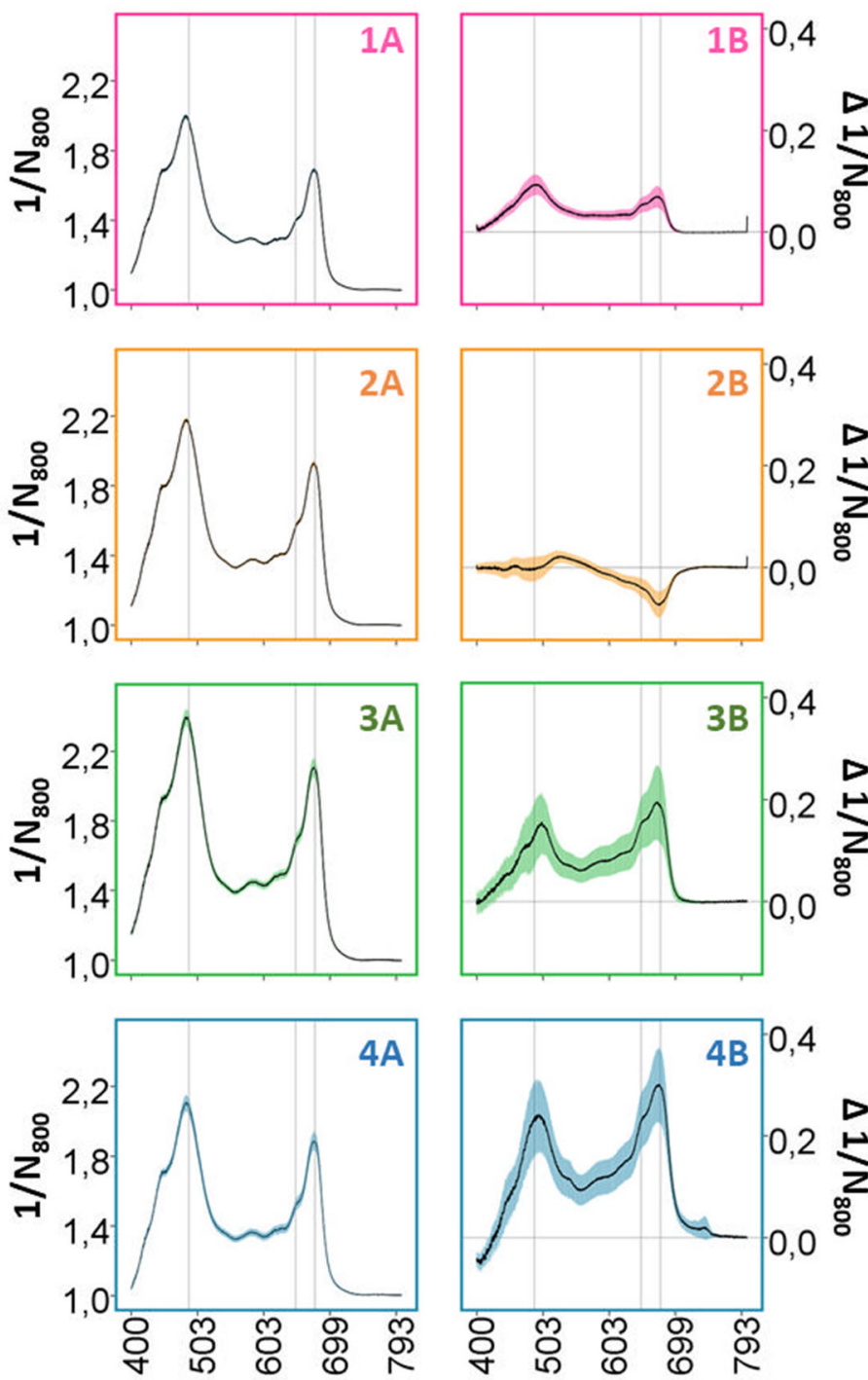

WAVELENGTH $(\mathrm{nm})$

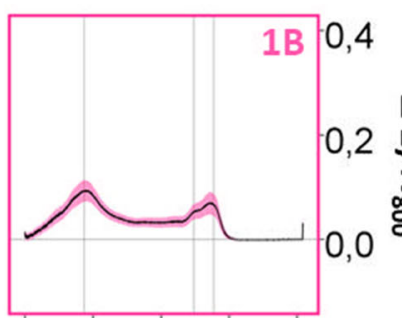

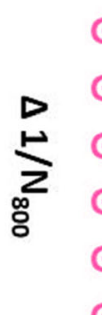

G. 28

G.29

G.05

G.26

G.69

G.21

G.82

G.12

G.71

G. 23

G.76

G.03

G.30

G.13

G.73

G.19

G.75

G.34

G. 27

G.77

G. 25

G.81

G. 83

G.16

G.24

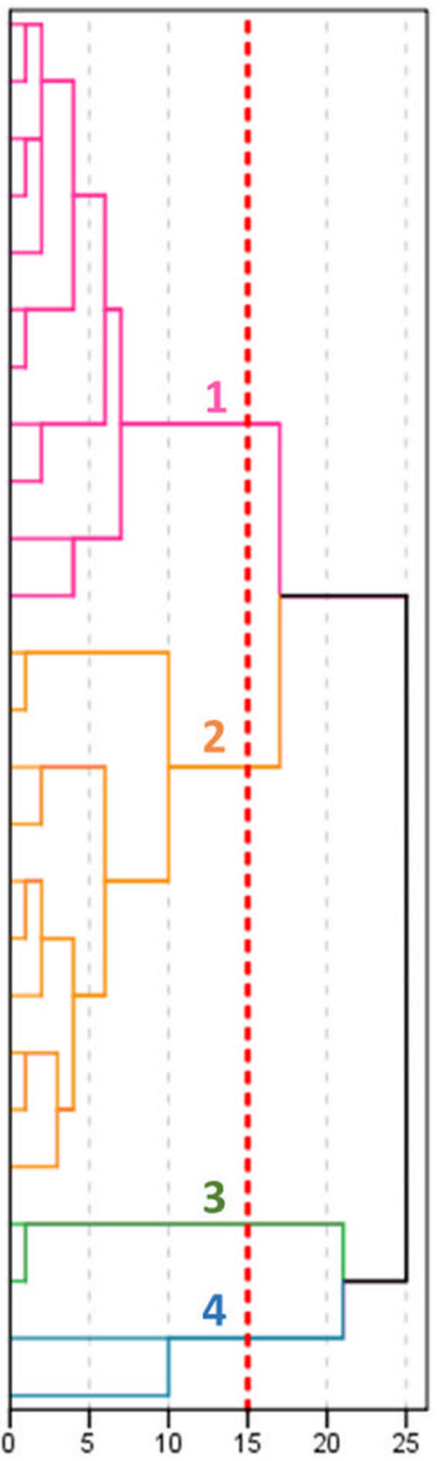

Fig. 5 Dendrogram obtained by the cluster analysis. On the left side of the figure, the average $1 / \mathrm{N}_{800}$ spectra (a) and $\Delta 1 / \mathrm{N}_{800} \mathrm{spectra}$ (stressed-watered) (b) are reported for each group (indicated by numbers-1, 2, 3, 4)

\section{Discussion}

Spectra similar to the one observed in this study (Fig. 3) were obtained by Rustioni et al. (2016). The presence of chlorophylls in the grapevine shoots, was also highlighted by Grossi et al. (2016), however, in previous case, due to the conservation treatment before reflectance measurements, the band was less evident. The photosynthetic activity of woody shoots in $V$. vinifera has been already demonstrated since 1971 (Kriedemann and Bottrose 1971) and the recent interpretations of the roles of corticular photosynthesis to cope drought emphasize the importance of this mechanism (Cernusak and Cheesma 2015; Vandegehuchte et al. 2015).

Rustioni et al. (2016), already observed a specificity of the spectral signature of woody tissues among different Vitis spp. In a physiological point of view, we can suggest that different genotypes have constitutively different levels of chlorophylls, and, thus, different propensity to recycle the respired carbon dioxide in vascular tissues. 

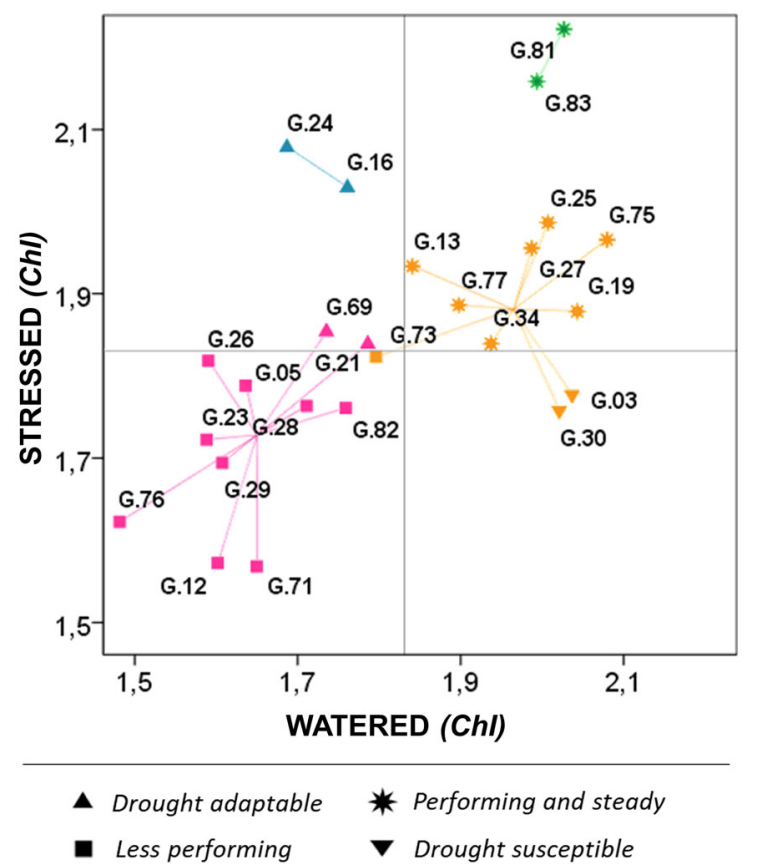

Fig. 6 Comparison of genotype performances under both watered and water stressed conditions, in terms of ChI. Gray lines indicate the threshold $(\mathrm{ChI}=1.83)$. The indicator shapes highlight the relative performances among the studied rootstocks. Colors are representative of the four groups obtained by cluster analysis (group $1=$ pink; group 2 = orange; group 3 = green; group $4=$ blue). Centroids are highlighted by lines connecting each group of rootstocks. (Color figure online)

Grossi et al. (2016) already reported modifications in the absorption spectra of vascular tissues due to water stress, however the modification trend was not univocal. Considering a higher number of genotypes, we can state that, generally, Vitis spp. plants respond to drought stress increasing the concentration of chlorophylls in woody tissues (nevertheless a variability among genotypes exists, as discussed in the following paragraphs). An increase in chlorophyll content should be considered as an index of the corticular photosynthesis stimulation in response to drought. This is coherent with the expectations, considering the main roles of corticular photosynthesis in diminish the danger of anaerobiosis (Aschan and Pfanz 2003), beside the possibility to improve the water use efficiency (Cernusak and Marshall 2000; Aschan and Pfanz 2003; Cernusak and Cheesma 2015) and the opportunity to recycle carbon resources when leaf photosynthesis is limited by stomata closure
(Cernusak and Cheesma 2015; Vandegehuchte et al. 2015).

Considering the chlorophyll $a$ and $b$ ratio, it is worth to notice that the indexes proposed by Rocchi et al. (2016) do not take into account the molar extinction coefficients of each chlorophyll in the red region. Lichtenthaler (1987) showed the lower absorption intensity of chlorophyll $b$ with respect to chlorophyll $a$ in the red region. Thus, this ratio could overestimate the real proportion among chlorophyll $a$ and $b$. Nevertheless, the obtained average value $(0.663 \pm 0.088)$ is unquestionably lower than the ones recorded by Tikhonov et al. (2017) in Vitis hybrids (2.5 in leaves, 2.2 in green shoots and 1.9 in cortex tissues). Thus, a clear trend appears in the $\mathrm{C}_{\mathrm{a}} \mathrm{I} / \mathrm{C}_{\mathrm{b}} \mathrm{I}$ ratio related to the expected amount of light rising the tissues and the probable contribution of the tissues to the total photosynthesis. Drought moves this ratio in wood to higher levels, toward the values of tissues with higher photosynthetic activity.

The concentration of photosynthetic pigments in woody tissues appeared to be strongly determined by genotypes. For the same plant material, in Bianchi et al. (2018), genotypes explained only $39 \%, 14 \%$ and $2 \%$ of the variability for starch, hydrophobicity and leaf transpiration respectively. Thus, chlorophyll contents appear to be mainly regulated by genotype. While, considering the pigment proportion, the variability was mainly explained by the environmental conditions.

Concerning the genotype classification, G.81; G.83; G.24 and G.16 resulted to be the most interesting genotypes and G.30 and G.03 the worst ones. Comparing these results with the ones reported in Bianchi et al. (2018), it is possible to note the ranking of genotype G.30 within the most interesting concerning the starch and hydrophobicity classifications. On the other hands, G.81; G.83; G.24 and G.16 showed bad performances concerning all the parameters considered in Bianchi et al. (2018). This could be explained by a strong induction of corticular photosynthesis as detoxification mechanism in plants particularly stressed by drought and vice versa. Finally, rootstock G.03, had bad performances concerning all the parameters considered in both the studies and could be an interesting negative reference in future studies.

In conclusion, the importance of corticular photosynthesis among the adaptation mechanisms of plants to drought was recently pointed out. In this work, we 
confirmed an adaptive mechanism to water stress involving the chlorophyll accumulation in woody tissues, coherent with this hypothesis. Considering woody tissue pigmentations, the chlorophyll concentration, and its increase in consequence to drought, appeared to be the main variability factors in genotype classification. This finding confirms the importance of the presence of photosynthetic pigments in stems. Of course, the activation of this response should be ascribed to some plant disfunctions caused by drought. Thus, it is also possible that plants not showing this behavior adopted different strategies to face the water stress, preventing the necessity of corticular photosynthesis stimulation. Further studies will be necessary to understand the synergies among the different tolerance mechanisms.

Finally, a first proposal of genotype classification based on their response to the stress in terms of chlorophyll concentrations and proportions was drawn. Nevertheless, further works will be necessary to improve the scientific knowledge on this topic and to confirm the behavior of each genotype in different years and locations. Future applications could include screening of large sized population, allowing a robust validation of hypothesis and methods.

Acknowledgements We acknowledge Lucio Brancadoro, Daniele Grossi, Davide T.G. Tincani, and Giovambattista Simone Di Lorenzo for the technical support.

Funding Open Access funding provided by Università del Salento.

Open Access This article is licensed under a Creative Commons Attribution 4.0 International License, which permits use, sharing, adaptation, distribution and reproduction in any medium or format, as long as you give appropriate credit to the original author(s) and the source, provide a link to the Creative Commons licence, and indicate if changes were made. The images or other third party material in this article are included in the article's Creative Commons licence, unless indicated otherwise in a credit line to the material. If material is not included in the article's Creative Commons licence and your intended use is not permitted by statutory regulation or exceeds the permitted use, you will need to obtain permission directly from the copyright holder. To view a copy of this licence, visit http://creativecommons.org/licenses/by/4.0/.

Data availability Data will be made available if requested to the corresponding author.

Code availability Microsoft Office Excel and SPSS statistical software (IBM SPSS Statistics 24).

\section{References}

Aschan G, Pfanz H (2003) Non-foliar photosynthesis-a strategy of additional carbon acquisition. Flora 198:81-97

Ávila E, Herrera A, Tezara W (2014) Contribution of stem $\mathrm{CO}_{2}$ fixation to whole-plant carbon balance in nonsucculent species. Photosynthetica 52(1):3-15

Bellvert J, Zarco-Tejada PJ, Girona J, Fereres E (2014) Mapping crop water stress index in a 'Pinot-noir' vineyard: comparing ground measurements with thermal remote sensing imagery from an unmanned aerial vehicle. Precis Agric 15:361-376

Bianchi D, Grossi D, Tincani DTG, Simone Di Lorenzo G, Brancadoro L, Rustioni L (2018) Multi-parameter characterization of water stress tolerance in Vitis hybrids for new rootstock selection. Plant Physiol Biochem 132:333-340

Bianchi D, Grossi D, Simone Di Lorenzo G, Zi Ying Y, Rustioni L, Brancadoro L (2020) Phenotyping of the "G series" Vitis hybrids: first screening of the mineral composition. Sci Hortic 264:109155

Cernusak LA, Cheesma AW (2015) The benefits of recycling: how photosynthetic bark can increase drought tolerance. New Phytol 208(4):995-997

Cernusak LA, Marshall JD (2000) Photosynthetic refixation in branches of western. White Pine Funct Ecol 14:300-311

Fini A, Bellasio C, Pollastri S, Tattini M, Ferrini F (2013) Water relations, growth, and leaf gas exchange as affected by water stress in Jatropha curcas. J Arid Environ 89:21-29

Grossi D, Rustioni L, Simone di Lorenzo G, Failla O, Brancadoro L (2016) Water deficit effects on grapevine woody tissue pigmentations. Hort Sci (Prague) 43(4):188-194

Herrera JC, Hochberg U, Degu A, Sabbatini P, Lazarovitch N, Castellarin SD, Fait A, Alberti G, Peterlunger E (2017) Grape metabolic response to postveraison water deficit is affected by interseason weather variability. J Agric Food Chem 65(29):5868-5878

Kriedemann PE, Bottrose MS (1971) Chlorophyll content and photosynthetic activity within woody shoots of Vitis vinifera (L.). Photosynthetica 5(1):22-27

Lichtenthaler HK (1987) Chlorophyll and carotenoids: pigments of photosynthetic biomembranes. Methods Enzymol 148:331-382

Lovisolo C, Lavoie-Lamoureux A, Tramontini S, Ferrandino A (2016) Grapevine adaptations to water stress: new perspectives about soil/plant interactions. Theor Exp Plant Physiol 28:53-66

Matese A, Baraldi R, Berton A, Cesaraccio C, Di Gennaro SF, Duce P, Facini O, Mameli MG, Piga A, Zaldei A (2018) Estimation of water stress in grapevines using proximal and remote sensing methods. Rem Sens 10:114

Merzlylyak MN, Solovchenko AE, Gitelson AA (2003) Reflectance spectral features and non- destructive estimation of chlorophyll, carotenoid and anthocyanin content in apple fruit. Postharvest Biol Technol 27:197-211

Migliaro D, De Lorenzis G, Simone Di Lorenzo G, De Nardi B, Gardiman M, Failla O, Brancadoro L, Crespan M (2019) Grapevine non-vinifera genetic diversity assessed by SSR markers as a starting-point for new grapevine rootstock 
breeding programs. Am J Enol Vitic. https://doi.org/10. 5344/ajev.2019.18054

Munné-Bosch S, Alegre L (2004) Die and let live: leaf senescence contributes to plant survival under drought stress. Funct Plant Biol 31(3):203-216

Nilsen T (1995) 10—stem photosynthesis: extent, patterns, and role in plant carbon economy. Plant stems. Physiology and functional morphology. Physiological ecology. Academic Press, Cambridge, pp 223-240

Rocchi L, Rustioni L, Failla O (2016) Chlorophylls and carotenoids quantification in white grape (Vitis vinifera L.) skins by reflectance spectroscopy. Vitis 55:11-16

Rustioni L, Ciacciulli A, Grossi D, Brancadoro L, Failla O (2016) Stem xylem characterization for Vitis drought tolerance. J Agric Food Chem 64:5317-5323

Saveyn A, Steppe K, Ubierna N, Dawson TE (2010) Woody tissue photosynthesis and its contribution to trunk growth and bud development in young plants. Plant Cell Environ 33:1949-1958

Tikhonov KG, Khristin MS, Klimov VV, Sundireva MA, Kreslavski VD, Sidorov RA, Tsidendambayev VD, Savchenko TV (2017) Structural and functional characteristics of photosynthetic apparatus of chlorophyll-containing grape vine tissue. Russ J Plant Physiol 64(1):73-82

Tyree MT, Ewers FW (1991) Tansley review No. 34. The hydraulic architecture of trees and other woody plants. New Phytol 119:345-360

Vandegehuchte MW, Bloemen J, Vergeynst LL, Steppe K (2015) Woody tissue photosynthesis in trees: salve on the wounds of drought? New Phytol 208:998-1002

Vaz M, Coelho R, Rato A, Samara-Lima R, Silva LL, Campostrini E, Mota JB (2016) Adaptive strategies of two Mediterranean grapevines varieties (Aragonez syn. Tempranillo and Trincadeira) face drought: physiological and structural responses. Theor Exp Plant Physiol 28:205-220

Zhang L, Marguerit E, Rossdeutsch L, Ollat N, Gambetta GA (2016) The influence of grapevine rootstocks on scion growth and drought resistance. Theor Exp Plant Physiol 28:143-157

Publisher's Note Springer Nature remains neutral with regard to jurisdictional claims in published maps and institutional affiliations. 